\title{
A Study of using AHP Method to Evaluate the Criteria and Attribute of Defects in Heritage Building
}

\author{
Siti Nor Fatimah Zuraidi ${ }^{*}$, Mohammad Ashraf Abdul Rahman ${ }^{1}$, Zainal Abidin Akasah ${ }^{2}$ \\ ${ }^{1}$ Facutly of Engineering Technology, Universiti Tun Hussein Onn Malaysia, 84600 Muar Johor, \\ Malaysia \\ ${ }^{2}$ Facutly of Civil \& Environmental Engineering, Universiti Tun Hussein Onn Malaysia, 86400 Batu \\ Pahat Johor, Malaysia
}

\begin{abstract}
This paper examines the criteria and attributes for assessing defects in a heritage building. The goal of this paper is to solve element type for building defects by using the Analytic Hierarchy Process (AHP). A survey questionnaire was develop based on the identified criteria and attributes of defect for a heritage building in Malaysia. The survey questionnaire was administered to consultants, academics, and contractors. A total of 20 expert panels was selected to determine the element of the defect in building performance. The sensitivity analysis of alternative ratings in respect to difference pairwise comparisons of the criteria and attribute was carried out. By changing one element in the pairwise comparison matrix, the process of defect element is monitored thus enabling possible improvements. An overall ranking of the Hierarchy priorities of criteria and attribute was a result of the AHP analysis. The result of the research is weightage for each criterion and its respective attributes. The criteria and attributes will be used as elements to develop a strategic heritage building performance procedure in Malaysia.
\end{abstract}

\section{Introduction}

In general, the element process is very complex for a heritage building. It is necessary to consider many different factors, such as building use, structural durability, building components, financial, building condition assessment, and others. Given the time perspective in heritage building planning, it is clear that the element in which a building operates is predicted for a relatively short time, and uncertainty increases with time [1]. Strategic planning is fundamental to closing the gap between rising resource flexibility and

\footnotetext{
* Corresponding author: timi gee@,yahoo.com
} 
uncertainty in the growth of damage. Taking into account all of the above, heritage buildings must decisions being made relating to the essential elements of the building and the structure of the building.

In Malaysia, conservation of heritage buildings is initiated by the government and the private sector [2]. The establishment of the National Heritage Department Malaysia in 2006 has shown the government's efforts to preserve the heritage buildings in Malaysia. The Department will ensure that all requirements of the National Heritage Act 2005 shall be complied with by each Authority. In addition, the listing of George Town and Malacca as a UNESCO Heritage Site on July 7, 2008, serves to make Malaysia a country that is keen to promote heritage tourism. Listing under the UNESCO heritage site will be supported by relevant stakeholders including building owners, technical professionals and competent persons, to ensure heritage conservation efforts in Malaysia are successful. To align demand and capacity building heritage, practice management needs an appropriate methodological approach to the planning process that reflects the essence of heritage buildings [3].

The aims of this paper are to solve the problem of choosing a heritage building element. The type of building and utilities should be chosen from the designated heritage building. Given that the problem is the manufacture of multiple criteria, the Analytical Hierarchy Process (AHP) is used to select the appropriate building element. Some areas where AHP has been successfully used include the selection of one attribute from many, resource allocations, and forecasts. Element selection is a process related to the building; therefore, the use of AHP is reasonable. The advantage of this decision-support tool is the last position obtained based on a paired pair rating of both criteria and options provided by the user. In addition, the AHP approach is used because the logic is rational and understandable, as well as the calculation process is quite simple. The authors are keen to analyze the sensitivity of alternative evaluations regarding the comparison of different pair criteria. By changing one element in a pairing matrix (while maintaining constants with others), the building element selection process is monitored thus allowing improvements to be made possible.

\section{Literature review}

The AHP method was developed by Thomas L. Saaty [4-5-6], a mathematician. This method is a framework for effective decision-making on complex issues by simplifying and speeding up the decision-making process by solving the problem into its parts, arranging these parts or variables in a hierarchical order, assigning numerical values to subjective considerations about the importance of each variable and synthesize these various considerations to determine which variable has the highest priority and act to influence the outcome of the situation [7]. This AHP method helps solve complex problems by structuring a hierarchy of criteria, stakeholders of results, and by drawing various considerations to develop weight or priorities [8]. This method also combines the strengths of the feelings and logic concerned on various issues, and then synthesizes various considerations into the results that match our estimates intuitively as presented in the consideration already made [8-9].

According to Saaty, there are three principles in solving the problem with AHP, namely the principle; Compose the hierarchy (Decomposition), the principle of prioritizing (Comparative Judgment), and the logical consistency principle (Logical Consistency) [4-5]. The AHP in question is a hierarchy of problems that will be solved to consider the criteria or component components that support the achievement of goals [9]. In the process of determining goals and objectives hierarchy, it is important to note whether the set of objectives and the relevant criteria are appropriate for the problems encountered. In 
selecting the criteria for each decision-making issue it is necessary to consider the following criteria: The criteria should be complete so that it covers all important aspects used in making decisions for achieving goals; Operations are in the sense that each of these criteria should have the meaning for the decision makers, so that they can really appreciate the existing alternatives; Avoid any criteria that essentially contain the same meaning, so create criteria based on the goal of focus; and Simplify the problem in the analysis [9-10].

The AHP in compiling the hierarchy depends on the type of decision to take. If the problem is to choose an alternative, we can start from the basic level by dragging all those alternatives. The next level should consist of criteria to consider the various alternatives. And the top level should be one element only, example focus or overall purpose [9]. There can be compared to the importance of each individual's contribution. And let criteria be taken as minimum material possible. Comparative Judgment means making judgments about the relative importance of two elements at a certain level in relation to the levels above. This assessment is the core of AHP, as it will affect the priority elements of the elements. The results of this assessment will be placed in a matrix called the pairwise comparison matrix [10].

In order to obtain a useful scale when comparing two elements, it is important to understand the general purpose. In compiling the scale of comparative importance in pairs according to Saaty, the benchmark reference in Table 1 is used. In the relative importance assessment of the two elements, a reciprocal axiom applies, meaning that if the element $i$ is assessed 3 times more important than $j$, then element $j$ must equal 1/3 times the significance rather than element $i$ [4]. Additionally, the comparison of the same two elements will result in a number 1, meaning equally important. Two different elements can be judged just as important. If there is $\mathrm{m}$ element, then it will obtain the pairwise comparison matrix of $m \mathrm{x}$ $n$. The number of judgments required in compiling this matrix is $n(n-1) / 2$ because the reciprocal matrix and the diagonal elements are equal to 1 . Synthesis of Priority from each pairwise comparison matrix then finds the eigenvector value for local priority. Since pairwise comparison matrices are present at each level, then to achieve global priority should be done synthesis between local priorities. Ordering elements according to relative importance through synthesis procedure is called priority setting. Logical Consistency has two meanings, the first is the same objection can be grouped according to uniformity and relevance. The second meaning is regarding the level of relationship between objects based on certain criteria [4-5-6].

Table 1. The fundamental scale

\begin{tabular}{|c|c|c|}
\hline Scale & Definition & Explanation \\
\hline 1 & Equal importance & Two activities contribute equally to the objective \\
\hline 3 & $\begin{array}{l}\text { Moderate importance of one } \\
\text { over another }\end{array}$ & $\begin{array}{l}\text { Experience and judgment strongly favor one activity } \\
\text { over another }\end{array}$ \\
\hline 5 & $\begin{array}{l}\text { Essential or strong } \\
\text { importance }\end{array}$ & $\begin{array}{l}\text { Experience and judgment strongly favor one activity } \\
\text { over another }\end{array}$ \\
\hline 7 & Very strong importance & $\begin{array}{l}\text { An activity is strongly favored and its dominance } \\
\text { demonstrated in practice }\end{array}$ \\
\hline 9 & Extreme importance & $\begin{array}{l}\text { The evidence favoring one activity over another is of } \\
\text { tile highest possible order of affirmation }\end{array}$ \\
\hline $2,4,6,8$ & $\begin{array}{l}\text { Intermediate values } \\
\text { between the two adjacent } \\
\text { judgments }\end{array}$ & When compromise is needed \\
\hline Reciprocals & \multicolumn{2}{|c|}{$\begin{array}{l}\text { If activity } i \text { has one of the above numbers assigned to it when compared with activity } \\
j \text {, then } j \text { has the reciprocal value when compared with } i\end{array}$} \\
\hline Rationals & $\begin{array}{l}\text { Ratios arising from the } \\
\text { scale }\end{array}$ & $\begin{array}{l}\text { If consistency were to be forced by obtaining } n \\
\text { numerical values to span the matrix }\end{array}$ \\
\hline
\end{tabular}




\section{Developing the case study}

The analytical hierarchy process is used to select alternatives or alternative priority arrangements, and then in this phase is an alternative development [13]. In order to prioritize, prioritizing issues should be able to be decomposed into goals of an activity, identification of options, and the formulation of criteria to choose priorities (Figure 1). The first step is to formulate the goals of a prioritizing activity. In the case of strategy formulation in selecting heritage building elements, the purpose of "selecting heritage building element" is to know the importance of each component within the building based on information or factual data and at the same time as a strategy evaluation of building predation to advance and develop through the overall criteria and existing aspects. For the case selection of heritage building elements, the purpose of the activity is to select and retrieve the most important heritage building elements.

To develop the case study, the stages proposed by Saaty [4-5-6-7] for using the AHP method were followed. There are three main phases of the AHP model methodology, namely: arrange problems in the hierarchy structure, arranging priorities for each element problem, rating synthesis and consistency of AHP.

\subsection{Arrange problems in hierarchy structure}

Every complex problem can be reviewed on a detailed and structured side. Below is a chart to define the criteria for achieving the goals:

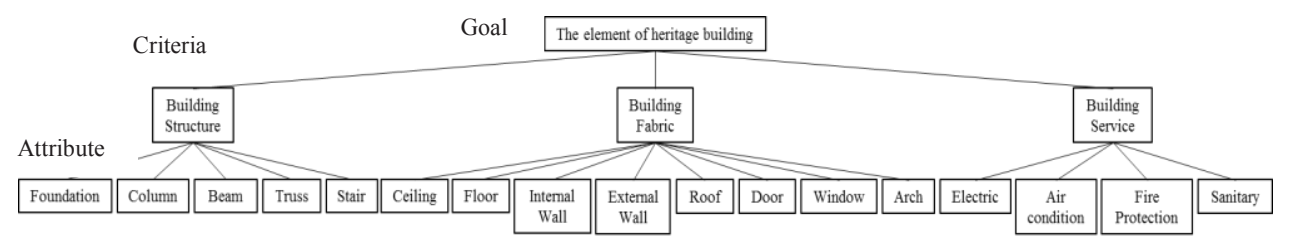

Fig.1. The hierarchical structure of the criteria

The identification of hierarchical structure in the study of the selection of elements of the heritage building is related to the performance of a building component. Once goals can be set, then the next step is to determine the criteria of that goal. For the case of choosing these heritage building elements, the criteria for the purpose are building the structure, building fabric, and building service. For the selection of attribute is the foundation, column, beam, truss, stair, ceiling, floors, roof, windows, doors, internal and external walls, arch, electric, air condition, fire protection and sanitary. These elements are important in the context of the heritage building.

\subsection{Arranging priorities for each element problem}

This process produces element weight on goal achievement, so the highest weighted element has the priority of handling. The first step at this stage is to compile paired comparisons that are transformed into matrix form so that this matrix is called a paired comparison matrix

After the problem is decomposition, then there are two stages of assessment or comparing between elements i.e. comparison between criteria and comparison between 
options for each criterion. Comparison between criteria is intended to determine the weight for each criterion. On the other hand, the comparison between options for each criterion is intended to see the weight of an option for a criterion. In other words, this assessment is intended to see how important an option is to be seen from certain criteria.

In comparison, experts who develop the AHP use a scale from 1/9 to 9. If selections A and $\mathrm{B}$ are identifiable, then $\mathrm{A}$ and $\mathrm{B}$ each is given a value of 1 . If for example, $\mathrm{A}$ is better / preferred than $\mathrm{B}$, then $\mathrm{A}$ is rated 3 and $\mathrm{B}$ is rated $1 / 3$. If $\mathrm{A}$ is much preferred over $\mathrm{B}$, then $\mathrm{A}$, for example, is given a value of 7 and $B$ given a $1 / 7$ value. This assessment will not be used in this paper because it is less logical. As an example, if $\mathrm{A}$ is 7 and $\mathrm{B}$ is $1 / 7$, then the difference between A and B is nearly $700 \%$.

Using the above illustration, the comparison between the criteria will result in the following Table 2. To facilitate, in the table it is assumed there are only three criteria. The table can be summarized as follows:

Table 2. Calculation of criteria

\begin{tabular}{lccc}
\hline Criteria & Building Structure & Building Fabric & Building Service \\
\hline Building Structure (C1) & 1 & 1 & 5 \\
Building Fabric (C2) & 1 & 1 & 3 \\
Building Service (C3) & $1 / 5$ & $1 / 3$ & 1 \\
\hline
\end{tabular}

By using the same procedure, then the comparison between the attributes for each of the criteria is made. The following Table 3 illustrates the comparison between the attributes ( 5 choices) for criteria $1(\mathrm{C} 1)$. The following is a comparison of options available on the criteria comparison table for $\mathrm{C} 1$, with the following explanation:

Table 3. Paired comparison matrix for the Building Structure (C1) attribute

\begin{tabular}{lccccc}
\hline Attribute & Foundation & Column & Beam & Truss & Stair \\
\hline Foundation & 1 & 3 & 3 & 5 & 7 \\
Column & $1 / 3$ & 1 & 1 & 5 & 5 \\
Beam & $1 / 3$ & 1 & 1 & 3 & 7 \\
Truss & $1 / 2$ & $1 / 2$ & $1 / 3$ & 1 & 3 \\
Stair & $1 / 7$ & $1 / 2$ & $1 / 7$ & $1 / 3$ & 1 \\
\hline
\end{tabular}

The following Table 4 and Table 5, illustrates a comparison between the attributes for criteria. The assessment process between these options continues to be conducted for all criteria. To note, the assessment should be done by its members and key stakeholders. Usually, the number of experts varies, depending on the availability of resources. Assessment can be done by distributing questionnaires to each member or by conducting a meeting of experts to conduct the assessment.

Table 4. Paired comparison matrix for the Building Fabric (C2) attribute

\begin{tabular}{lcccccccc}
\hline Building Fabric & Ceiling & Floor & $\begin{array}{c}\text { Internal } \\
\text { Wall }\end{array}$ & $\begin{array}{c}\text { External } \\
\text { Wall }\end{array}$ & Roof & Door & Window & Arch \\
\hline Ceiling & 1 & 1 & 1 & 1 & 3 & 3 & 5 & 5 \\
Floor & 1 & 1 & 3 & 3 & 3 & 7 & 7 & 7 \\
Internal Wall & 1 & $1 / 3$ & 1 & 1 & 3 & 5 & 5 & 7 \\
External Wall & 1 & $1 / 3$ & 1 & 1 & 3 & 5 & 5 & 5 \\
Roof & $1 / 3$ & $1 / 3$ & $1 / 3$ & $1 / 3$ & 1 & 3 & 5 & 7 \\
Door & $1 / 3$ & $1 / 7$ & $1 / 2$ & $1 / 2$ & $1 / 3$ & 1 & 3 & 5 \\
\hline
\end{tabular}




\begin{tabular}{lllllllcc}
\hline Window & $1 / 2$ & $1 / 7$ & $1 / 2$ & $1 / 2$ & $1 / 2$ & $1 / 3$ & 1 & 3 \\
Arch & $1 / 2$ & $1 / 7$ & $1 / 7$ & $1 / 2$ & $1 / 7$ & $1 / 2$ & $1 / 3$ & 1 \\
\hline
\end{tabular}

Table 5. Paired comparison matrix for the Building Service (C3) attribute

\begin{tabular}{lcccc}
\hline Building Service & Electric & Air Condition & Fire Protection & Sanitary \\
\hline Electric & 1 & 3 & 3 & 7 \\
Air Condition & $1 / 3$ & 1 & 3 & 5 \\
Fire Protection & $1 / 3$ & $1 / 3$ & 1 & 3 \\
Sanitary & $1 / 7$ & $1 / 5$ & $1 / 3$ & 1 \\
\hline
\end{tabular}

\subsection{Rating synthesis}

The synthesis of assessment results is the final stage of AHP. Basically, this synthesis is the sum of the weights obtained from each attribute after weighing the criteria. In general, the value of an option is as follows:

$$
\begin{aligned}
& \frac{w_{i}}{w_{j}} \\
& =a_{i j}(i, j \\
& =1,2, \ldots, n) \\
& w_{i}=\text { input value in row } \\
& w_{j}=\text { input value in column }
\end{aligned}
$$

The formula can also be presented in the form of tables. To simplify, assuming there are three criteria with five attributes like Table 6 below. For example, the priority weight of the building structure is obtained by multiplying the weighted value of the criteria with the values attributes as follows:

$$
a_{i j} w_{j(i, j=1,2, \ldots, n)}
$$

$$
w_{i}=
$$

Table 6. Pairwise comparison matrix for the first level

\begin{tabular}{lcccc}
\hline Criteria & Building Structure & $\begin{array}{c}\text { Building } \\
\text { Fabric }\end{array}$ & $\begin{array}{c}\text { Building } \\
\text { Service }\end{array}$ & $\begin{array}{c}\text { Priority } \\
\text { Vector }\end{array}$ \\
\hline Building Structure & 1.000 & 1.000 & 5.000 & 0.481 \\
Building Fabric & 1.000 & 1.000 & 3.000 & 0.405 \\
Building Service & 0.200 & 0.333 & 1.000 & 0.114 \\
\hline
\end{tabular}

The following Table 7 to Table 9, is made identical to criteria of building fabric and building service. The assessment process between these attributes continues to be conducted for all criteria. By comparing the values obtained for each choice, priority can be sorted based on the magnitude of that value. The higher the value of an option, the higher the priority

Table 7. Paired comparison matrix for the Building Structure attribute in $\%$

\begin{tabular}{lccccccc}
\hline $\begin{array}{l}\text { Building } \\
\text { Structure }\end{array}$ & Foundation & Column & Beam & Truss & Stair & $\begin{array}{c}\text { Relative } \\
\text { priority }\end{array}$ & $\begin{array}{c}\text { Relative } \\
\text { Priority } \\
(\%)\end{array}$ \\
\hline $\begin{array}{l}\text { Foundation } \\
\text { Column }\end{array}$ & 1.000 & 3.000 & 3.000 & 5.000 & 7.000 & 0.458 & $45.8 \%$ \\
\hline
\end{tabular}




\begin{tabular}{lccccccc}
\hline Beam & 0.333 & 1.000 & 1.000 & 3.000 & 7.000 & 0.207 & $20.7 \%$ \\
Truss & 0.200 & 0.200 & 0.333 & 1.000 & 3.000 & 0.076 & $7.6 \%$ \\
Stair & 0.143 & 0.200 & 0.143 & 0.333 & 1.000 & 0.039 & $3.9 \%$ \\
\hline
\end{tabular}

$\lambda_{\max }=5.227 \quad C I=0.057 \quad C R=0.051 \leq 0.1 \approx$ Consistent

Table 8. Paired comparison matrix for the Building Fabric attribute in $\%$

\begin{tabular}{lcccccccccc}
\hline $\begin{array}{l}\text { Building } \\
\text { Fabric }\end{array}$ & Ceiling & Floor & $\begin{array}{c}\text { Internal } \\
\text { Wall }\end{array}$ & $\begin{array}{c}\text { External } \\
\text { Wall }\end{array}$ & Roof & Door & Window & Arch & $\begin{array}{c}\text { Relative } \\
\text { priority }\end{array}$ & $\begin{array}{c}\text { Relative } \\
\text { Priority } \\
(\%)\end{array}$ \\
\hline Ceiling & 1.000 & 1.000 & 1.000 & 1.000 & 3.000 & 3.000 & 5.000 & 5.000 & 0.087 & $8.7 \%$ \\
Floor & 1.000 & 1.000 & 3.000 & 3.000 & 3.000 & 7.000 & 7.000 & 7.000 & 0.317 & $31.7 \%$ \\
Internal & 1.000 & 0.333 & 1.000 & 1.000 & 3.000 & 5.000 & 5.000 & 7.000 & 0.188 & $18.8 \%$ \\
Wall & & & & & & & & & & $18.4 \%$ \\
External & 1.000 & 0.333 & 1.000 & 1.000 & 3.000 & 5.000 & 5.000 & 5.000 & 0.184 & \\
Wall & 0.333 & 0.333 & 0.333 & 0.333 & 1.000 & 3.000 & 5.000 & 7.000 & 0.121 & $12.1 \%$ \\
Roof & 0.333 & 0.143 & 0.200 & 0.200 & 0.333 & 1.000 & 3.000 & 5.000 & 0.050 & $5.0 \%$ \\
Door & 0.200 & 0.143 & 0.200 & 0.200 & 0.200 & 0.333 & 1.000 & 3.000 & 0.031 & $3.1 \%$ \\
Window & 0.200 & 0.143 & 0.143 & 0.200 & 0.143 & 0.200 & 0.333 & 1.000 & 0.021 & $2.1 \%$ \\
Arch & \multicolumn{7}{c}{$C I=0.111$} & \multicolumn{7}{c}{$C=0.079 \leq 0.1 \approx$ Consistent } & &
\end{tabular}

Table 9. Paired comparison matrix for the Building Service attribute in \%

\begin{tabular}{lcccccc}
\hline Building Service & Electric & Air Condition & Fire Protection & Sanitary & $\begin{array}{c}\text { Relative } \\
\text { priority }\end{array}$ & $\begin{array}{c}\text { Relative } \\
\text { Priority }(\%)\end{array}$ \\
\hline Electric & 1.000 & 3.000 & 3.000 & 7.000 & 0.525 & $52.5 \%$ \\
Air Condition & 0.333 & 1.000 & 3.000 & 5.000 & 0.279 & $27.9 \%$ \\
Fire Protection & 0.333 & 0.333 & 1.000 & 3.000 & 0.139 & $13.9 \%$ \\
Sanitary & 0.143 & 0.200 & 0.333 & 1.000 & 0.057 & $5.7 \%$ \\
\hline \multicolumn{2}{c}{$\lambda_{\max }=4.140$} & $C I=0.047$ & $C R=0.052 \leq 0.1 \approx$ Consistent & &
\end{tabular}

\section{Example for AHP manual calculation:}

Step 1: Change matrix to a decimal number:

$\left[\begin{array}{lll}1.000 & 1.000 & 5.000 \\ 1.000 & 1.000 & 3.000 \\ 0.200 & 0.333 & 1.000\end{array}\right]$

Step 2: Iteration 1:

Quadratic this matrix above:

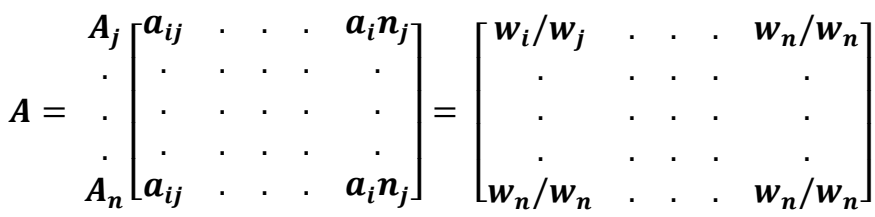

(1)

$\frac{w_{i}}{w_{j}}=a_{i j}(i, j=1,2, \ldots, n)$

$w_{i}=$ input value in row

$w_{j}=$ input value in column 


$$
\begin{aligned}
& A=\left[\begin{array}{lll}
1.000 & 1.000 & 5.000 \\
1.000 & 1.000 & 3.000 \\
0.200 & 0.333 & 1.000
\end{array}\right] \\
& A=\left[\begin{array}{lll}
1.000 & 1.000 & 5.000 \\
1.000 & 1.000 & 3.000 \\
0.200 & 0.333 & 1.000
\end{array}\right] \times\left[\begin{array}{lll}
1.000 & 1.000 & 5.000 \\
1.000 & 1.000 & 3.000 \\
0.200 & 0.333 & 1.000
\end{array}\right] \\
& w_{i}=a_{i j} w_{j(i, j=1,2, \ldots, n)}
\end{aligned}
$$

(2)

$w_{i}=$ average from $a_{i 1} w_{n}$

$w_{11}=(1.000)^{2}+(1.000)^{2}+(5.000 \times 0.200)=3.000$

$w_{12}=(1.000)^{2}+(1.000)^{2}+(5.000 \times 0.333)=3.665$

$w_{13}=(1.000 \times 5.000)+(1.000 \times 3.000)+(5.000 \times 1.000)=13.000$

$w_{21}=(1.000)^{2}+(1.000)^{2}+(3.000 \times 0.200)=2.600$

$w_{22}=(1.000)^{2}+(1.000)^{2}+(3.000 \times 0.333)=2.999$

$w_{23}=(1.000 \times 5.000)+(1.000 \times 3.000)+(3.000 \times 1.000)=11.000$

$w_{31}=(0.200 \times 1.000)+(0.333 \times 1.000)+(1.000 \times 0.200)=0.733$

$w_{32}=(0.200 \times 1.000)+(0.333 \times 1.000)+(1.000 \times 0.333)=0.866$

$w_{33}=(0.200 \times 5.000)+(0.333 \times 3.000)+(1.000)^{2}=2.999$

$$
A=\left[\begin{array}{ccc}
3.000 & 3.665 & 13.000 \\
2.600 & 2.999 & 11.000 \\
0.733 & 0.866 & 2.999
\end{array}\right]
$$

Normal Value

$$
\left[\begin{array}{ccc}
3.000 & 3.665 & 13.000 \\
2.600 & 2.999 & 11.000 \\
0.733 & 0.866 & 2.999
\end{array}\right]
$$

\begin{tabular}{c} 
Total Row \\
\hline 19.665 \\
16.599 \\
4.598 \\
40.862
\end{tabular}

Priority vector

0.481

0.406

0.113

1.000

Step 3: Iteration 2:

Quadratic this matrix below:

$$
\begin{aligned}
A= & {\left[\begin{array}{lll}
3.000 & 3.665 & 13.000 \\
2.600 & 2.999 & 11.000 \\
0.733 & 0.866 & 2.999
\end{array}\right] } \\
A= & {\left[\begin{array}{lll}
3.000 & 3.665 & 13.000 \\
2.600 & 2.999 & 11.000 \\
0.733 & 0.866 & 2.999
\end{array}\right] \times\left[\begin{array}{lll}
3.000 & 3.665 & 13.000 \\
2.600 & 2.999 & 11.000 \\
0.733 & 0.866 & 2.999
\end{array}\right] } \\
w_{11} & =(3.000)^{2}+(3.665 \times 2.600)+(13.000 \times 0.733)=28.058 \\
w_{12} & =(3.000 \times 3.665)+(3.665 \times 2.999)+(13.000 \times 0.866)=33.244 \\
w_{13} & =(3.000 \times 13.000)+(3.665 \times 11.000)+(13.000 \times 2.999)=118.302 \\
w_{21} & =(2.600 \times 3.000)+(2.999 \times 2.600)+(11.000 \times 0.733)=23.660 \\
w_{22} & =(2.600 \times 3.665)+(2.999)^{2}+(11.000 \times 0.866)=28.049 \\
w_{23} & =(2.600 \times 13.000)+(2.999 \times 11.000)+(11.000 \times 2.999)=99.778 \\
w_{31} & =(0.733 \times 3.000)+(0.866 \times 2.600)+(2.999 \times 0.733)=6.649 \\
w_{32} & =(0.733 \times 3.665)+(0.866 \times 2.999)+(2.999 \times 0.866)=7.881 \\
w_{33} & =(0.733 \times 13.000)+(0.866 \times 11.000)+(2.999)^{2}=28.049
\end{aligned}
$$




$$
A=\left[\begin{array}{ccc}
28.058 & 33.244 & 118.302 \\
23.660 & 28.049 & 99.778 \\
6.649 & 7.881 & 28.049
\end{array}\right]
$$

$\left[\begin{array}{ccc}28.058 & \text { Normal value } \\ 23.660 & 28.049 & 99.718 .302 \\ 6.649 & 7.881 & 28.049\end{array}\right]$

$\frac{\text { Total Row }}{179.604}$
151.487
42.579
373.670

\begin{tabular}{c} 
Priority vector \\
\hline 0.481 \\
0.405 \\
0.114 \\
1.000
\end{tabular}

Step 4: The difference of Iteration 1 with Iteration 2:
0.481
0.481
0.000
0.406
$-0.405=0.001$
0.113
0.114
0.001

Step 5: Iteration 3:

Table 10 shown Pairwise Comparison Matrix and Eigen Value:

Table 10. Ranking of criteria

\begin{tabular}{lccccc}
\hline Criteria & $\begin{array}{c}\text { Building } \\
\text { Structure }\end{array}$ & $\begin{array}{c}\text { Building } \\
\text { Fabric }\end{array}$ & $\begin{array}{c}\text { Building } \\
\text { Service }\end{array}$ & Priority Vector & Rank \\
\hline Building & 1.000 & 1.000 & 5.000 & 0.481 & 1 \\
Structure & 1.000 & 1.000 & 3.000 & 0.405 & 2 \\
Building Fabric & 0.200 & 0.333 & 1.000 & 0.114 & 3 \\
Building & & & & \\
Service & & &
\end{tabular}

\subsection{Consistency of AHP}

If aij represents the degree of importance of factor $i$ to factor $\mathrm{j}$ and asserts the importance of factor $j$ to factor $k$, so that the decision becomes consistent, the importance of factor $i$ to factor $k$ should be equal to a $i j . a j k$ or if a $i j . a j k=a i k$ for all $i, j, k$ then the matrix is consistent. Problems in the measurement of human opinion, consistency cannot be enforced. If $A>B$ (e.g. $2>1$ ) and $\mathrm{C}>\mathrm{B}$ (e.g. 3>1), it cannot be forced that $\mathrm{C}>\mathrm{A}$ with the number $6>1$ even though it is consistent. The collection of opinions between one factor and another is free from one another, and this can lead to the incompetence of respondents' responses. However, too many inconsistencies are also unnecessary. Repetition of interviews on the same number of respondents is sometimes required when the degree of inconsistency is large. According to Saaty, has proven that the consistency index of the matrix of $n$ can be obtained by the formula:

$C I=\left(\frac{\lambda_{\max }-n}{(n-1)}\right)$

The largest eigenvalues are obtained by summing the results of multiplying the number of columns with the main vector eigen. For example, using Tables 6 , the largest eigenvalues obtained:

$V A=a_{i j \mathrm{x}} V P$ with $V A=\left(V_{a i}\right)$

$V B=\frac{V A}{V P}$ with $V B=\left(V_{b i}\right)$

$V B_{\text {i for } \mathrm{I}=1,2, \ldots, n}$

$V A=V B=$ between vector 


$$
\begin{aligned}
& V_{A}=\left(\frac{(1.000 \times 0.481)+(1.000 \times 0.405)+(5.000 \times 0.114)}{0.481}\right)=3.027 \\
& V_{B}=\left(\frac{(1.000 \times 0.481)+(1.000 \times 0.405)+(3.000 \times 0.114)}{0.405}\right)=3.032 \\
& V_{C}=\left(\frac{(0.200 \times 0.481)+(0.333 \times 0.405)+(1.000 \times 0.114)}{0.114}\right)=3.026 \\
& \lambda_{\text {max }}=\frac{1}{n} \sum \boldsymbol{a}_{i j} \\
& \lambda_{\text {max }}=\frac{(3.027+3.032+3.026)}{3} \\
& \lambda_{\text {max }}=3.028
\end{aligned}
$$

Since the matrix is 3 (i.e. consists of 3 factors), the value of the consistency index obtained:

$$
\begin{aligned}
& \boldsymbol{C I}=\left(\frac{\lambda_{\max }-n}{(n-1)}\right) \\
& C I=\left(\frac{3.028-3}{(3-1)}\right) \\
& C I=0.014
\end{aligned}
$$

If $C I$ is 0 , it means that the matrix is consistent. Determine the inconsistency limit of Saaty, measured using the Consistency Ratio $(C R)$, consisting of consistency indices comparing with random generator values $(R I)$ that are listed in Table 11 . This value depends on the matrix order $n$ accordingly; the consistency ratio can be formulated as follows:

$C R=\left(\frac{C I}{R I}\right)$

Random Index (RI) is a Consistency Index of the randomly defined reciprocal matrix. In Table 11 it can be seen the average of RI for various matrix sizes

Table 11: Random Inconsistency Index $(R I)$ for $n=1,2 \ldots 10$

\begin{tabular}{lcccccccccc}
\hline$n$ & 1 & 2 & 3 & 4 & 5 & 6 & 7 & 8 & 9 & 10 \\
\hline$R I$ & 0.00 & 0.00 & 0.58 & 0.90 & 1.12 & 1.24 & 1.32 & 1.41 & 1.45 & 1.49 \\
\hline
\end{tabular}

For example, continue the values of the respondents listed in Table 10, value:

$$
\begin{aligned}
& \boldsymbol{C R}=\left(\frac{C I}{\boldsymbol{R I}}\right) \\
& C R=\left(\frac{0.014}{0.58}\right) \\
& C R=0.024 \leq 0.1 \approx \text { Consistent }
\end{aligned}
$$

If the $\mathrm{CR}$ value matrix is less than $10 \%$, the inconsistency of the opinion is still considered acceptable. The above calculation is continued for level 3, so the primary eigenvector value and C.R. at each level can be obtained. Composite weight is used to determine the weight and overall consistency. Average geometry is used for the average end result of some respondents. 
For the building structure, building fabric and building service attributes, the same processes for determining the $\mathrm{CR}$ above were used. For example, the matrix for building a structure (see Table 6) has $\mathrm{CR}=0.024$, which is considered a good level of consistency, with an index below the recommended. The same applies to the other matrices. It was possible to conclude that all the matrices have judgments with a high level of consistency.

After providing a comparison of paired comparisons and calculating relative preferences, it is possible to establish the final decision structure of the AHP model to evaluate the criteria and attribute of defects in the heritage building. According to AHP, the element heritage building which is the most important is for is a building structure is a foundation, for building fabric is the floor and for building service is electric. This result is expected because of the fact that all elements in heritage building are important for their function. Arch have lower importance priority weightage from other.

\section{Data processing and analysis}

The data processing went through several stages; identification, setting the perspective of the main consumer criteria based on consumer needs, and then data are obtained from interviews with management. The information obtained is, of course, the basis of the research that will then be made into a questionnaire and processed using the software. Subsequently, the setting of subcritical perspective on the basis of observation of research conducted in the consumer area is located.

From the data collection described above further, this questionnaire is conducted and disseminated. The questionnaire is then directed to the designated respondent consisting of professional engineers, academicians, consultants and conservators in particular engaged in the field of heritage conservation. From the respondents replies the consistency of the answers can be found. To find out the questionnaire answers are read and those seen alone are deemed inconsistent and thus the answer cannot be used for further data processing.

After calculating the ratio analysis with the aim to get the inconsistency ratio in the hierarchy of selection of heritage building elements, then the inconsistency ratio in this decision hierarchy is obtained the consistency of the decision. When data collection on the software has been obtained, then the process of weighting paired with each of the criteria or between the attributes can be solved.

From the calculation in the processing process we can know the final result of this research, namely the weighting of the main criteria as well as the pairing attributes and any criteria that the respondents are most interested in. From the results of the survey, the details of the questionnaire spread on the important elements of the legacy building. In this research, these building elements are divided into three basic criteria of choice, namely building the structure, building fabric, and building service. While the underlying things are our curiosity as management, how effective and efficient is whether the criterion of building fabric and building services is separated from the perspective of actual quality. So we can know how far their chances are to choose the criteria; based on the three perspectives of the criterion described above.

Secondary data collection focused on literature assessment of the situation in terms of heritage building elements so that secondary data can support the research hypothesis conducted by the researcher. The condition of the development of building assessments, especially elements of heritage buildings form data is obtained from the mass media or from competent government agencies in the field. To complete it, the researcher use additional data that is sourced from books and websites.

\subsection{Result analysis}


Based on the model's equation, according to Eq. (1) to (5), and the hierarchical structure of the criteria in Figure 1, a model with three museums to evaluate outsourced defects has been created. Museums A, B, and C at the Pahang rally were taken as case studies. To do so, scores on a 1-5 scale are set up with increasing importance for each attribute, and therefore every museum will be measured. Table 12 shows the detail of the weightage of the museum A.

Table 12. A case study of museum A

\begin{tabular}{|l|l|c|c|c|}
\hline Criteria & \multicolumn{1}{|c|}{ Attribute } & Weightage & Score & $\begin{array}{c}\text { Weightage } \\
\text { Score }\end{array}$ \\
\hline \multirow{4}{*}{$\begin{array}{c}\text { Building } \\
\text { Structure }\end{array}$} & Foundation & 0.220 & 5 & 1.100 \\
\cline { 2 - 5 } & Column & 0.106 & 4 & 0.424 \\
\cline { 2 - 5 } & Beam & 0.099 & 5 & 0.495 \\
\cline { 2 - 5 } & Truss & 0.037 & 5 & 0.185 \\
\cline { 2 - 5 } & Stair & 0.019 & 4 & 0.076 \\
\hline \multirow{5}{*}{ Building Fabric } & Ceiling & 0.035 & 4 & 0.140 \\
\cline { 2 - 5 } & Floor & 0.128 & 4 & 0.512 \\
\cline { 2 - 5 } & Internal Wall & 0.076 & 3 & 0.228 \\
\cline { 2 - 5 } & External Wall & 0.075 & 3 & 0.225 \\
\cline { 2 - 5 } & Roof & 0.049 & 4 & 0.196 \\
\cline { 2 - 5 } & Door & 0.020 & 4 & 0.080 \\
\cline { 2 - 5 } & Window & 0.013 & 3 & 0.039 \\
\cline { 2 - 5 } & Arch & 0.009 & 5 & 0.036 \\
\hline & Electric & 0.060 & 5 & 0.030 \\
\cline { 2 - 5 } & Air Condition & 0.032 & 5 & 0.160 \\
\cline { 2 - 5 } & Fire Protection & 0.016 & 4 & 0.080 \\
\cline { 2 - 5 } & Sanitary & 0.006 & Final score & $\mathbf{4 . 0 3 0}$ \\
\hline
\end{tabular}

The same procedure has been carried out to obtain weighting for museums B and C. Table 13 shows the final classification obtained by the AHP model to assess the criteria and nature of the situation in the heritage building, in descending order.

Table 13. Final score for museum A, B, and C

\begin{tabular}{|c|c|}
\hline Museum & Score \\
\hline $\mathrm{A}$ & 4.030 \\
\hline $\mathrm{B}$ & 3.861 \\
\hline $\mathrm{C}$ & 3.772 \\
\hline
\end{tabular}

Museum A has the highest weightage score of 4.030, making it the museum with the best ratings in accordance with the purpose of achieving the objectives of each museum is in good condition. Therefore, museum A only needs to make scheduled maintenance to maintain the museum in the best possible condition and reduce any damage or defects in the heritage building elements. In addition, the museum authority should strive to improve the performance of museum building elements such as maintenance action requirements e.g. monitoring, repair, replacement to prevent serious defects or damage to ensure the safety of the building to last.

\section{Conclusion}

This case study is aimed at assessing the important criteria of building elements and heritage building conditions from any defects found in the museums under study, using the AHP method. This model is specifically designed to identify important elements in the 
building to evaluate the state of heritage building performance. This model is tested on three museum buildings located in the state of Pahang, where data collection begins; through semi-structured group interviews, the information needed to begin developing the proposed model is obtained, and the most important criteria and attributes for the problem assessment process have been identified.

The hierarchical structure is provided with the participation of decision makers, followed by the comparison corresponding to criteria and attributes. Furthermore, the consistency of paired matrix properties has been confirmed. In each of the two-stage criteria, priority analysis is used to obtain relative importance of the comparison matrix and has been uninformed to have the same magnitude. Therefore, to determine the objective function according to ranking criteria and their relative priorities, enabling the proposed model was tested in all three museums to assess the condition of the building elements. By developing the equations (1) to (5), which represent the objective function, the general goal of the work is achieved. After developing an objective function and building a valuation model, the predetermined objectives have also been achieved.

Due to this limitation, it was important to know the use of case study, as the model should not be used generally for situations and other outside segments that are used. In addition, it is difficult to collect all interview participants together at the same time; because it is a structured group interview, there are many cases where participants cannot be involved simultaneously. Another limitation is the need for all research participants involved in the process to commit to it. As a contribution, this study highlights the adoption of multi-criteria methodologies used in the maintenance services sector, more specifically in heritage buildings. To continue this study, we propose to apply this model to all national heritage management with efficient tools in the decision-making process.

This research has been supported by the Mybrain15, Postgraduate Student Center \& Research Management Centre, University Tun Hussein Onn Malaysia, for making this publication possible.

\section{References}

1. S. N. F. Zuraidi, M. A. A. Rahman, \& Z. A. Akasah, Kriteria Penting Untuk Mengukur Keadaan Bangunan Warisan. Malaysian Journal of Social Sciences, Vol. 1(1), 92-102. (2018)

2. S. N. Harun, Heritage building conservation in Malaysia: Experience and challenges. Procedia Engineering, 20, 41-53. (2011).

3. M. A. A. Rahman, Z. A. Akasah \& S. N. F. Zuraidi, An Analysis of Current Demographic Trends of Maintenance Personnel of A Heritage Buildings in Malaysia, International Journal of Advanced Science Engineering Information Technology, Vol.2 (2), (2012)

4. T. L. Saaty, The Analytic Hierarchic Process. New York: McGraw Hill; 1980.

5. T. L. Saaty, How to make a decision: The Analytic Hierarchy Process. European Journal of Operational Research, Vol.48, pp. 9-26. (1990)

6. T. L. Saaty, Decision making for leaders - the Analytic Hierarchy Process for decisions in a complex world. Pittsburgh: RWS, (2000)

7. T. L. Saaty, The Analytic Hierarchy and Analytic Network Processes for the Measurement of Intangible Criteria and for Decision-Making. In: Figueira, J, Greco, S, Ehrgott, M, editors. Multiple criteria decision analysis: State of the art surveys, New York: Springer, pp. 345-407. (2005) 
8. E. Salgado, V. A. P. Salomon, C. Mello, Analytic hierarchy prioritization of new product development activities for electronics manufacturing. International Journal of Production Research, Vol. 50, pp. 4860-4866. (2012)

9. C. Garuti, V. A. P. Salomon, Compatibility indices between priority vectors. International Journal of the Analytic Hierarchy Process, Vol. 4, pp. 152-160. (2012)

10. M. An AHP Approach to Aircraft Selection Process. Transportation Research Procedia, Vol. 3, pp. 165-174. (2014)

11. S. N. F. Zuraidi, M. A. A. Rahman, \& Z. A. Akasah, Current Issues and Challenges of the Future In Heritage Building Maintenance at Malaysia: Literature Review, Journal of Humanities, Language, Culture and Business, Vol. 1(4), pp. 13-21 (2017)

12. S. Dožić \& M. Kalić, An AHP approach to aircraft selection process. Transportation Research Procedia, Vol. 3, pp. 165-174. (2014)

13. R. Yin, Case Study Research: design and methods. 4th edition. London: Sage, (2009) 